\title{
The Emotional Personality of Psychotherapists: A Pilot Research with Gestalt-Therapy Clinicians
}

\section{Antonio Alcaro ${ }^{1}$, Serena Iacono Isidoro ${ }^{2}$, David Conversi ${ }^{1}$, Alessandra Accoto ${ }^{1}$, Margherita Spagnuolo Lobb²}

\author{
${ }^{1}$ Department of Psychology, Sapienza University of Rome, Rome, Italy \\ ${ }^{2}$ Istituto di Gestalt HCC, Palermo, Italy \\ Email: antonioalcaro@yahoo.it, serena.iacono@gestalt.it, david.conversi@uniroma1.it, \\ alessandra.accoto@uniroma1.it,margherita.spagnuolo@gestalt.it
}

How to cite this paper: Alcaro, A., Isidoro, S. I., Conversi, D., Accoto, A., \& Spagnuolo Lobb, M. (2020). The Emotional Personality of Psychotherapists: A Pilot Research with Gestalt-Therapy Clinicians. Psychology, 11, 1628-1645.

https://doi.org/10.4236/psych.2020.1111103

Received: September 15, 2020

Accepted: November 10, 2020

Published: November 13, 2020

Copyright $\odot 2020$ by author(s) and Scientific Research Publishing Inc. This work is licensed under the Creative Commons Attribution International License (CC BY 4.0).

http://creativecommons.org/licenses/by/4.0/ (c) (i) Open Access

\begin{abstract}
Since the discovery of "countertransference", it was recognized that the therapist's personality plays an important role in determining the course of psychotherapy. However, systematic empirical works on this topic have been sparse compared to the enormous amount of theoretical literature. Therefore, in the following pilot study, the emotional profile of psychotherapists was investigated using the Affective Neuroscience Personality Scales (ANPS), a quantitative measure of the basic emotional foundations of human personality based on Jaak Panksepp's neuro-ethological studies. More specifically, we submitted the ANPS to a population of Gestalt-therapists to ascertain if they share a characteristic emotional profile (1) and if the emotional traits of personality are related to specific intersubjective competences (2). Our results show that, compared with normal population, the personality of therapists is characterized by higher expression of PLAYFULNESS/joy, CARE/nurturance and Spirituality, as well as a significant decrease in the expression of the RAGE/anger disposition. Such emotional traits, that are not influenced by the experience of training, correlate with important relational skills such as empathy, reflective functioning and interoceptive awareness. Therefore, unlearned emotional dispositions have high relevance in the development of the therapist's sensitivity to the phenomenological intersubjective field, a competence recently called "Aesthetic Relational Knowledge" in a contemporary Gestalt-approach. Our findings may have implications for training therapists and optimizing treatment outcomes.
\end{abstract}

\section{Keywords}

Emotion, Personality, Psychotherapist, Interpersonal Skills, Gestalt Therapy 


\section{Introduction}

The personal involvement of the therapist in the clinical work with patients was first recognized by Freud et al. (1910), who introduced the term "countertransference" to refer to an analyst's emotional response to the patient (Gabbard, 2014). In subsequent psychoanalytic elaborations, countertransference was considered not just an obstacle to be overcome, but instead the main road to clinical knowledge, as the feelings that the patients induce in their therapist communicate something important about their inner world (Winnicott, 1949; Heimann, 1950; Greenberg, 2001). Moreover, most current psychotherapeutic approaches recognized the clinical relevance of therapist's emotional reactions and attribute to the affective intersubjective environment the main role in determining the course of the clinical outcomes (Dahl et al., 2012; Flückiger et al., 2018, Lingiardi et al., 2018; Heinonen \& Nissen-Lie, 2020).

In consequence of that, an essential part of the clinical work for psychotherapists has reserved to the process of managing the emotional relational field evoked in the here and now of the therapeutic relationship (Stern, 2004). A contemporary evolution of the concept of intersubjective sensitivity, developed within a Gestalt therapy approach, is that of Aesthetic Relational Knowledge (Spagnuolo Lobb, 2017a, 2017b, 2018), defined as "the way in which the therapist uses her senses to understand the patient's situation through embodied empathy (i.e. identification with the patient's experience) and resonance (i.e. personal and sensitive reaction to the field in front of the patient)" (Spagnuolo Lobb, 2018: pp. 27-28).

Although the importance of therapist's emotional competence has been widely recognized, systematic empirical work has been sparse compared to the enormous amount of theoretical literature on the subject. Consequently, the characteristics that may underlie the differential effectiveness of the therapist work remain largely unknown (Beutler et al., 2004). Moreover, it is still unclear to which extent the treatment process is influenced by therapist's acquired technical skills or by other, more personal, factors, such as his private lives, his individual history and his personality profile (Dinger et al., 2009; Hersoug et al., 2001, 2009). Therefore, further empirical research is needed to identify those qualities that might influence therapeutic change (Kazdin, 2009; Norcross \& Wampold, 2011).

Between all personal factors influencing therapist's competence, those related to the emotional personality should be considered with special attention, since they have a deep impact in affective relations and emotional communication (Schore, 1994). Interestingly, the emotional brain systems at the foundation of human personality have been identified by the neuro-ethological investigations of Jaak Panksepp and collaborators (Panksepp, 1998; Panksepp \& Biven, 2012), and their findings have been operationalized by Davis and collaborators with a psychometric instrument called the Affective Neuroscience Personality Scales (ANPS) (Davis et al., 2003). ANPS is a self-report questionnaire measuring the expression of three positive and three negative emotional dispositions in the daily 
life of the subject. The positive emotional dispositions are SEEKING/interest (being curious, exploring, striving for solutions to problems, positively anticipating new experiences), CARING/nurturance (being drawn to young children and pets, feeling soft-hearted toward animals and people in need, feeling empathy) and PLAYFULNESS/joy (having fun, playing games with physical contacts, humour, and laughter). The negative emotional dispositions are FEAR/anxiety (feeling tense, worrying, struggling with decisions, ruminating), ANGER/rage (feeling hot-headed, being easily irritated and frustrated, experiencing frustration leading to anger, expressing anger verbally or physically), SADNESS/separation distress (feeling lonely, crying frequently, thinking about loved ones and past relationships, and feeling distress). These systems (capitalizations reflect a specialized scientific terminology) are conceptualized as emotional endophenotypes, i.e. emotional markers of underlying neuropsychological activities that lie between genes and behaviours (Panksepp, 2006; Davis \& Panksepp, 2011). A scale called Spirituality is added to the other six ANPS scales and it has been defined as "feeling connected to humanity and creation as a whole, feeling a sense of oneness with creation, striving for inner peace and harmony, searching for meaning in life" (cf. Davis et al., 2003).

Since its discovery more than 15 years ago (Davis et al., 2003), the ANPS was used to investigate the emotional profile of individuals suffering from neurological or psychopathological diseases (Coenen et al., 2011; Farinelli et al., 2015; Karterud et al., 2016; Montag et al., 2016; 2017; Fuchshuber et al., 2019; Karterud et al., 2016; Wernicke et al., 2019; Pulver et al., 2020). However, for the first time we decide here to administer the ANPS to a population of psychotherapists. Our main goal was to ascertain if clinicians belonging to a Gestalt therapy approach share some common characteristic emotional profile. Moreover, we also tested possible correlations between the ANPS emotional scales and certain relational and emotional abilities intrinsically related to the concept of Aesthetic Relational Knowledge. As shown in the following sessions, our study shows the relevance of unlearned emotional dispositions for the therapist intersubjective sensitivity.

\section{Present Study}

In this study we aim to trace the emotional profile of psychotherapistsadministering the ANPS to a population of Gestalt psychotherapists and students. To increase the homogeneity of our sample, we select a group of psychotherapists belonging to a single therapeutic approach. The reason why we choose the Gestalt therapy approach is that it fits very well with Panksepp's Affective Neuroscience in sharing the relevance given to emotional feelings, considered as the fundamental core of all subjective experiences (Perls, Hefferline, \& Goodman, 1951; Bloom, 2009; Spagnuolo Lobb, 2013; Alcaro, Carta, \& Panksepp, 2017; Francesetti, Alcaro, \& Settanni, 2020). Gestalt therapy is a humanistic approach which draws on three main epistemological roots (cfr. Perls et al., 1951): 1) Phenomenological: interested in the experience as it unfolds (Polster, 1987; 
Spagnuolo Lobb, 2013; Bloom, 2009); 2) Aesthetic: informed by senses (Spagnuolo Lobb et. al., 2018); 3) Field oriented: includes the feeling of the therapist (Jacobs \& Hycner, 2009; Macaluso, 2018; Robine, 2001, 2015; Spagnuolo Lobb, 2018; Yontef, 2001). As a phenomenological approach, Gestalt therapists work with what they can experience, in particular with what happens between them and client, in the between, the here and now of their therapeutic relationship. And they are interested in the process: what happens now, from moment to moment, how they develop contact with the client. The phenomenological focus brings them to be interested not so much in explaining the experience of the client, as in what is vital in it, how her suffering includes intentionality, excitement, and creative adjustment to a difficult situation. The aesthetic focus implies the use of their senses to recognize the client's way of being vital: the intentionality of contact that has been neglected by significant others and is still resilient (Spagnuolo Lobb, 2013, 2014). Finally, in Gestalt therapy we refer to the organism/environment field as a unitary experience (Perls et al., 1994, p. 4 ff.). When a client tells us something, we look at how she tells us (the aesthetics of it)nervously moving her leg or looking at the ceiling, for example-and we pay attention to what we, therapists, feel, since we are part of the client's experience at that moment. Our field oriented perspective brings us to consider what resonance does the experience of being with that client have for us. What emotion is activated in the field we share with her? All this contextualized and embodied understanding of the patient's relational suffering requires that the therapist is able to feel her own bodily feelings, to reflect on them and to develop embodied empathy. Aesthetic Relational Knowledge allows the therapist to support the client's intentionality and creative adjustment (Spagnuolo Lobb, 2018), with a specific relational support tailored on that client.

We administered the ANPS to the group of Gestalt psychotherapists and we compared the scales of therapists with the mean scales of normal population obtained in the ANPS Italian validation study (Giacolini et al., 2017). Moreover, we also administer the ANPS to a group of students enrolled in the first year of the specialization school for Gestalt psychotherapists. Comparing the ANPS scales of therapists with those of students we could ascertain if the characteristic emotional profile of therapists is due to the effect of training. Finally, after the ANPS, we also administer three other tests that give different measures of intersubjective ability both to the group of psychotherapists and to the group of students. We then evaluated possible correlations between ANPS scales and the scales of intersubjective ability. The tests used were the RFQ8 for reflective functioning (Fonagy et al., 2016; Morandotti et al., 2018), the EQ15 for empathy (Allison et al., 2011; Senese et al., 2016), the MAIA for interoceptive awareness (Mehling et al., 2012, Calì et al., 2015).

In sum, with the present empirical investigation, we intend to pursuit three main goals:

1) To evaluate if the population of psychotherapists share a characteristic 
emotional profile that differ from that presented by normal Italian population;

2) To evaluate if (eventual) emotional differences revealed in psychotherapists are due to the experience of training, which also include a personal therapy, or to some pre-existing traits that predispose to choose such professional route;

3) To evaluate if the emotional scales of ANPS present correlations with some index of relational competence (reflexive function, bodily awareness, empathic quotient) that can partly reveal the Aesthetic Relational Knowledge.

\section{Methods}

\section{Subjects and sample size}

The study has involved ninety-two adults, 70 women $(76.1 \%)$ and 14 men (15.2\%), for 8 (8.7\%) subjects it was not possible to determine the gender from the questionnaires. They were divided in two groups:

- 41 students enrolled at the first year of Gestalt therapy training, 34 women (82.9\%) and 7 men (17.1\%) from the three different locations of Istituto di Gestalt HCC Italy (Milan, Palermo, Siracusa), age 25 - 52 (32.12 \pm 7.18 );

- 51 Gestalt psychotherapists (25 Gestalt psychotherapists for all the questionnaires), 36 women (70.6\%) and 7 men (13.7\%), age 31 - 64 (44.77 \pm 8.61$)$.

All participants gave their informed consent before taking part in the study on voluntary basis.

\subsection{Measures}

The Affective Neuroscience Personality Scales (ANPS) is a self-report questionnaire that assesses the conscious feelings and behavioral tendencies activated by primary emotional dispositions identified by the neuro-ethological studies of Panksepp and collaborators (Davis et al., 2003; Davis \& Panksepp, 2011). The ANPS has been developed to reflect individual variation in six basic emotional tendencies: SEEKING/curiosity, PLAYFULNESS/joy, CARE/nurturance, FEAR/ anxiety, ANGER/rage, and SADNESS/separation distress. All such scales are composed by 14 items. An operationalization of a construct called Spirituality (12 items) is also implemented in the ANPS. 16 filler items were designed as Dominance (7 items), Desirability (6 items) and social anxiety" 3 items. The scoring procedure for ANPS is to arrange the item scores from 0 - 3. Then, adding the item scored gives a range of scale scores from 0 - 42. Previous validation analyses using this instrument revealed good reliabilities of the ANPS (Cronbach alphas range: 0.77 - 0.89), gender and longitudinal measurement invariance, mean score stability over time, and external validity.

In such study, we used the Italian version of the ANPS 2.4, that has been recently validated by Giacolini et al. (2017) and here we used the version validated by Giacolini and collaborators. Each ANPS subscale comprised 14 items, answered on a 4-point Likert scale (totally disagree-disagree-agree-totally agree). The 14 items (half are reverse coded) are summed to obtain the score of the subscale. 
The Reflective Functioning Questionnaire-8 (RFQ-8) is a self-report questionnaire designed for RF assessment (Fonagy et al., 2016). The RFQ measures the degree of certainty/uncertainty the respondents experience in relation to their knowledge about their own and others' mental states. The eight items included in the RFQ-8 were all part of the original RFQ (54 questions) with findings providing preliminary evidence for its reliability and validity (Fonagy et al., 2016). Examples of questions are: "I always know what I feel" or "People's thoughts are a mystery to me." Every question in the RFQ is to be answered on a Likert scale from 1, indicating that the respondent "strongly disagrees," to 7, indicating that the respondent "strongly agrees." The RFQ has two subscales, which assess certainty (RFQ_C) and uncertainty (RFQ_U) about the mental states of self and others. High scores on these subscales indicate two distinct impairments in RF, respectively, hypomentalizing and hypermentalizing: hypomentalizing reflects concrete thinking and poor understanding of the mental states of self and others, while hypermentalizing refers to an "over-mentalizing" attitude, that is, developing too certain and detailed models of the mind and mental states not supported by the evidence (Morandotti et al., 2018). All of the items that make up RFQ-8 are median-scored items. For instance, "I don't always know why I do what I do" is a median-scored item used in the calculation of both the certainty and uncertainty scale. To calculate the RFQ_C score on this item, the scores were recoded to "3-2-1-0-0-0-0". The highest score would be obtained by choosing alternative 1-“strongly disagree", yielding a score of 3 on the certainty scale for this item. To calculate the RFQ_U score, the polarization would be the other way: $0-0-0-0-1-2-3$. The highest score on the uncertainty scale would be obtained by choosing alternative 7-"strongly agree," yielding a score of 3 . The RFQ-8 questionnaire is relatively new and has no well-established or validated cut-off for clinically high scores on its scales (Kristiansen et al., 2019). The total score for each of the scales in this study was calculated by adding together the scores and dividing by the number of items included. The cut-off was set at 1 for both scales. Scores above 1 were categorized as high (impaired), and scores below were categorized as low/normal. This cut-off was set based on the assumption that a mean score of at least one on either of these scales represents a marked mentalizing style.

The Empathy Quotient (EQ-15; Allison et al., 2011; Senese et al., 2016) is a 15 item self-report questionnaire for the assessment of empathy. The EQ-15 comprises a main scale for the assessment of global empathy and several subscales for the assessment of specific aspects of empathy (e.g., emotional reactivity or social skills). However, the subscales are highly inter-correlated with one another (Muncer \& Ling, 2006; Allison et al., 2011), implying that the EQ-15 measures empathy as an unidimensional rather than multidimensional construct. Following previous recommendations (Muncer \& Ling, 2006; Allison et al., 2011), we only considered the main scale in our analyses.

The Multidimensional Assessment of Interoceptive Awareness (MAIA) is a 
self-report measure for the assessment of emotional-bodily activation and interoceptive awareness. It consists of 8-scale state-trait questionnaire with 32 items to measure multiple dimensions of interoception on a 6-point Likert scale (from $0=$ never, to 5 = always), where higher values indicate higher levels of positive awareness. The MAIA's eight scales corresponding to its 8 -factor structure (Mehling et al. 2012; Calì et al., 2015). These are labeled Noticing (the ability to detect and distinguish uncomfortable, comfortable and neutral bodily feelings), Not-Distracting (the tendency not to ignore or distract oneself from feelings of pain or discomfort), Not-Worrying (the tendency not to react with anxiety or concern to feelings of pain or discomfort), Attention Regulation (the ability to support and control attention to bodily sensations), Emotional Awareness (awareness of the connection between bodily sensations and emotional states), Self-Regulation (the ability to regulate psychological distress through attention to bodily sensations), Body Listening (actively listening to the body for understanding), and Trust (living your body as safe and trustworthy). Non-Distracting indicates the tendency to ignore or distract oneself from sensations of pain or discomfort. Not-Worrying indicates emotional distress or worry with sensations of pain or discomfort.

\subsection{Procedures}

Before administering the selected measures, participants were briefly instructed about the tests. The study followed the Ethics research guidelines of the Istituto di Gestalt HCC Italy.

The battery of tests was administered in the same order: ANPS, RFQ_8, EQ_15, MAIA.

The student group has completed all the questionnaires during the first seminar of the first year of Gestalt therapy training.

As regards to the Gestalt psychotherapists group, only 25 psychotherapists have completed all the questionnaires (mean age $42.94 \pm 6.68$ ), and 18 have completed only the ANPS.

\subsection{Statistical Analysis}

Age and questionnaires data (ANPS, MAIA, RFQ-8 and EQ-15) were analyzed using Student's t-tests for independent samples, analysis of covariance (ANCOVA) and Pearson's correlation. The assumptions of variance equality (Levine's test, Box M test) and normality distribution (Shapiro-Wilk test) were evaluated and, in case of significant violations, Welch's t-test for unequal variances and Kruskal-Wallis non-parametric tests were used.

\subsection{Results}

Non-clinical adults vs psychotherapists For each ANPS scale, published means and standard deviations (SDs) from a sample of Italian non-clinical adults ( $\mathrm{n}=$ 299, age: 20 - 78) were extracted (Giacolini et al., 2017, Table 5) and compared to 
means and SDs from a sample of Italian psychotherapists $(n=51$, age: 25 - 64) using two-tailed Student's t-tests for independent samples.

Compared to non-clinical adults (Table 1), psychotherapists had, on average, significantly higher scores on the PLAY, CARE, SPIRITUALITY and GENERAL POSITIVE AFFECT scales, while they had lower scores on the ANGER scale and did not differ on the SEEK, FEAR, SADNESS, and GENERAL NEGATIVE AFFECT scales.

\section{Psychotherapy students vs skilled psychotherapists}

Group descriptives and statistical analyses for all the questionnaires data are shown, respectively, in Table 2 and Table 3. Regarding the ANPS, no significant departures from the assumptions underlying parametric tests were observed. We did not observe any significant difference between psychotherapy students vs skilled psychotherapists.

Regarding the MAIA test, statistically significant departures from normality were observed for all scales, while departures in variance homogeneity were significant for all scales except for "Not-distracting" and "Not-worrying". Welch's t-test for unequal variances evidenced that the skilled psychotherapists had significantly higher scores than students on all scales except for the "Not-worrying" one.

Regarding the RFQ-8 test, statistically significant departures from normality and variance equality were observed for both the RFQ-C or RFQ-U indices. Welch's t-test for unequal variances did not reveal any between-groups difference for either variables.

Regarding the EQ-15 test, statistically significant departures were observed only from normality for the "TOT" and "Cognitive Empathy" indices.

Since, the psychotherapy students $(n=41,32.1 \pm 7.18)$ were significantly

Table 1. ANPS scores from psychotherapists compared to non-clinical adults.

\begin{tabular}{cccccccc}
\hline \multirow{2}{*}{ ANPS } & \multicolumn{2}{c}{ Non-clinical adults } & \multicolumn{2}{c}{ Psychotherapists } & \multicolumn{3}{c}{ Independent Sample T-Test } \\
\cline { 2 - 8 } & mean & sd & mean & sd & Student's $\mathbf{~}$ & df & p \\
\hline PLAY & 24.72 & 5.07 & 26.70 & 4.26 & 2.63 & 348 & 0.01 \\
SEEK & 26.79 & 5.29 & 28.00 & 3.83 & 1.56 & 348 & 0.12 \\
CARE & 29.38 & 5.12 & 31.40 & 4.39 & 2.66 & 348 & 0.01 \\
FEAR & 24.67 & 6.17 & 23.50 & 6.05 & -1.26 & 348 & 0.21 \\
ANGER & 19.57 & 5.74 & 17.60 & 5.38 & -2.29 & 348 & 0.02 \\
SADNESS & 23.86 & 5.4 & 23.30 & 4.59 & -0.70 & 348 & 0.49 \\
SPIRITUALITY & 17.29 & 5.84 & 21.70 & 4.59 & 5.13 & 348 & 0.00 \\
GPA & 80.89 & 11.68 & 86.10 & 9.04 & 3.03 & 348 & 0.00 \\
GPN & 68.09 & 14.33 & 64.50 & 12.1 & -1.69 & 348 & 0.09 \\
DOMINANCE & 8.15 & 2.83 & 7.82 & 2.24 & -0.79 & 348 & 0.43 \\
SOCIAL ANXIETY & 4.31 & 1.9 & 4.24 & 1.66 & -0.25 & 348 & 0.80 \\
\hline
\end{tabular}


Table 2. ANPS, MAIA, RQF-8 and EQ-15 data from psychotherapy students and skilled psychotherapists.

\begin{tabular}{|c|c|c|c|c|c|}
\hline \multicolumn{2}{|c|}{ Questionnaire } & \multirow{2}{*}{$\begin{array}{l}\text { Group } \\
\text { Students }\end{array}$} & \multirow{2}{*}{$\begin{array}{l}\mathbf{N} \\
41\end{array}$} & \multirow{2}{*}{$\begin{array}{l}\text { Mean } \\
29.41\end{array}$} & \multirow{2}{*}{$\begin{array}{l}\text { SD } \\
4.31\end{array}$} \\
\hline ANPS & SEEKING & & & & \\
\hline & & skilled psychotherapists & 51 & 27.98 & 3.83 \\
\hline & PLAY & Students & 41 & 26.90 & 5.45 \\
\hline & & skilled psychotherapists & 51 & 26.75 & 4.26 \\
\hline & CARE & Students & 41 & 31.49 & 4.84 \\
\hline & & skilled psychotherapists & 51 & 31.39 & 4.39 \\
\hline & FEAR & Students & 41 & 25.59 & 5.34 \\
\hline & & Skilled psychotherapists & 51 & 23.55 & 6.05 \\
\hline & ANGER & Students & 41 & 18.22 & 4.34 \\
\hline & & Skilled psychotherapists & 51 & 17.65 & 5.38 \\
\hline & SADNESS & Students & 41 & 24.63 & 4.86 \\
\hline & & Skilled psychotherapists & 51 & 23.31 & 4.59 \\
\hline & SPIRITUALITY & Students & 41 & 20.10 & 5.86 \\
\hline & & Skilled psychotherapists & 51 & 21.73 & 4.59 \\
\hline & GPA & Students & 41 & 87.80 & 11.91 \\
\hline & & Skilled psychotherapists & 51 & 86.08 & 9.04 \\
\hline & GPN & Students & 41 & 68.44 & 12.29 \\
\hline & & Skilled psychotherapists & 51 & 64.51 & 12.11 \\
\hline \multirow[t]{16}{*}{ MAIA } & Noticing & Students & 39 & 3.54 & 0.76 \\
\hline & & Skilled psychotherapists & 24 & 3.96 & 0.46 \\
\hline & Not-distracting & Students & 39 & 2.26 & 0.88 \\
\hline & & Skilled psychotherapists & 24 & 2.70 & 0.74 \\
\hline & Not-worrying & Students & 39 & 2.64 & 0.93 \\
\hline & & Skilled psychotherapists & 24 & 2.98 & 1.05 \\
\hline & Attention Regulation & Students & 39 & 2.62 & 1.04 \\
\hline & & Skilled psychotherapists & 24 & 3.45 & 0.64 \\
\hline & Emotional awareness & Students & 39 & 3.64 & 1.04 \\
\hline & & Skilled psychotherapists & 24 & 4.12 & 0.42 \\
\hline & Self-regulation & Students & 39 & 3.08 & 1.09 \\
\hline & & Skilled psychotherapists & 24 & 3.54 & 0.68 \\
\hline & Body Listening & Students & 39 & 2.82 & 1.19 \\
\hline & & Skilled psychotherapists & 24 & 3.61 & 0.58 \\
\hline & Trusting & Students & 39 & 3.28 & 1.23 \\
\hline & & Skilled psychotherapists & 24 & 4.08 & 0.81 \\
\hline RFQ_8 & RFQ_C & Students & 39 & 1.67 & 0.87 \\
\hline
\end{tabular}


A. Alcaro et al.

\section{Continued}

\begin{tabular}{|c|c|c|c|c|c|}
\hline & & Skilled psychotherapists & 24 & 1.61 & 0.61 \\
\hline & RFQ_U & Students & 39 & 0.33 & 0.48 \\
\hline & & Skilled psychotherapists & 24 & 0.19 & 0.26 \\
\hline \multirow[t]{8}{*}{ EQ-15 } & TOT & Students & 39 & 19.87 & 4.35 \\
\hline & & Skilled psychotherapists & 24 & 19.33 & 2.87 \\
\hline & Cognitive Empathy & Students & 39 & 5.56 & 2.04 \\
\hline & & Skilled psychotherapists & 24 & 5.50 & 1.44 \\
\hline & Emotional Reactivity & Students & 39 & 7.36 & 1.60 \\
\hline & & Skilled psychotherapists & 24 & 6.75 & 1.45 \\
\hline & Social Skills & Students & 39 & 6.95 & 2.54 \\
\hline & & Skilled psychotherapists & 24 & 7.08 & 1.74 \\
\hline
\end{tabular}

Table 3. Statistical comparison (independent sample t-tests) between psychotherapy students and skilled psychotherapists with regard to ANPS, MAIA, RFQ_U and EQ-15 questionnaires.

\begin{tabular}{|c|c|c|c|c|c|}
\hline \multicolumn{2}{|c|}{ Questionnaire } & \multicolumn{2}{|l|}{ Statistic } & \multirow{2}{*}{$\begin{array}{l}\mathbf{d f} \\
90\end{array}$} & \multirow{2}{*}{$\frac{\mathbf{p}}{0.10}$} \\
\hline ANPS & SEEKING & Student's t & 1.69 & & \\
\hline & PLAY & Student's t & 0.16 & 90 & 0.88 \\
\hline & CARE & Student's t & 0.10 & 90 & 0.92 \\
\hline & FEAR & Student's t & 1.69 & 90 & 0.10 \\
\hline & ANGER & Student's t & 0.55 & 90 & 0.58 \\
\hline & SADNESS & Student's t & 1.34 & 90 & 0.19 \\
\hline & SPIRITUALITY & Student's t & -1.49 & 90 & 0.14 \\
\hline & GPA & Student's t & 0.79 & 90 & 0.43 \\
\hline & GNA & Student's t & 1.54 & 90 & 0.13 \\
\hline \multirow[t]{8}{*}{ MAIA } & Trusting & Welch's t & -3.08 & 60.7 & 0.00 \\
\hline & Body Listening & Welch's t & -3.51 & 58.7 & 0.00 \\
\hline & Self-regulation & Welch's t & -2.07 & 60.9 & 0.04 \\
\hline & Emotional awareness & Welch's t & -2.55 & 54.3 & 0.01 \\
\hline & Attention Regulation & Welch's t & -3.97 & 61 & 0.00 \\
\hline & Not-worrying & Welch's t & -1.30 & 44.5 & 0.20 \\
\hline & Not-distracting & Welch's t & -2.17 & 55.4 & 0.03 \\
\hline & Noticing & Welch's t & -2.73 & 61 & 0.01 \\
\hline \multirow[t]{2}{*}{ RFQ_8 } & RFQ_C & Welch's t & 0.29 & 59.8 & 0.77 \\
\hline & RFQ_U & Welch's t & 1.52 & 60.5 & 0.14 \\
\hline \multirow[t]{4}{*}{ EQ-15 } & TOT & Student's t & 0.54 & 61 & 0.59 \\
\hline & Cognitive Empathy & Student's t & 0.14 & 61 & 0.89 \\
\hline & Emotional Reactivity & Student's $\mathrm{t}$ & 1.52 & 61 & 0.13 \\
\hline & Social Skills & Student's $\mathrm{t}$ & -0.23 & 61 & 0.82 \\
\hline
\end{tabular}


younger $\left(\chi^{2}=34.7, \mathrm{df}=1, p<0.001\right)$ than skilled psychotherapists $(\mathrm{n}=42,44.8$ \pm 8.64 ) on average, we performed an ANCOVA for each scale to control for the potentially confounding effect of age. However, including age as a covariate did not modify the pattern of statistically significant differences observed with the independent samples t-test (data not shown).

Correlations in the combined sample of psychotherapy students and skilled psychotherapists

The matrix of correlations between the ANPS variables and each of the MAIA, RFQ-8 and EQ-15 questionnaires variables are shown in Table 4.

\section{Discussion}

As shown in the result section, our study with the ANPS shows that psychotherapists share a common emotional profile of personality that differs from standard population. Specifically, Gestalt therapists are characterized by higher scores in the emotional scales of CARING/nurturance, PLAYFULNESS/joy and Spirituality. On the other hand, psychotherapists show lower scores in the scale of ANGER/rage. No significant differences between psychotherapists and normal population have been revealed for the scales of SEEKING/curiosity, FEAR/ anxiety and SADNESS/separation distress. However, SEEKING tends to be higher in psychotherapists and FEAR and SADNESS tend to be higher in normal population.

Table 4. Correlations between the ANPS and each of the MAIA, RFQ_8 and EQ-15 with regard to the combined sample of psychotherapy students and skilled psychotherapists.

\begin{tabular}{|c|c|c|c|c|c|c|c|c|c|c|}
\hline \multirow{2}{*}{\multicolumn{2}{|c|}{ Questionnaire }} & \multicolumn{9}{|c|}{ ANPS } \\
\hline & & \multirow{2}{*}{$\begin{array}{c}\text { SEEK } \\
0.01\end{array}$} & \multirow{2}{*}{$\begin{array}{l}\text { PLAY } \\
-0.14\end{array}$} & \multirow{2}{*}{$\begin{array}{c}\text { CARE } \\
-0.18\end{array}$} & \multirow{2}{*}{$\begin{array}{l}\text { FEAR } \\
-0.21\end{array}$} & \multirow{2}{*}{$\begin{array}{c}\text { ANGER } \\
-0.13\end{array}$} & \multirow{2}{*}{$\begin{array}{c}\text { SADNESS } \\
-0.24\end{array}$} & \multirow{2}{*}{$\begin{array}{c}\text { SPIRIT. } \\
0.17\end{array}$} & \multirow{2}{*}{$\begin{array}{l}\text { GPA } \\
-0.14\end{array}$} & \multirow{2}{*}{$\begin{array}{c}\text { GNA } \\
-0.248^{*}\end{array}$} \\
\hline MAIA & Noticing & & & & & & & & & \\
\hline & Not-distracting & 0.13 & 0.10 & -0.10 & $-0.263^{\star}$ & -0.18 & $-0.376^{\star *}$ & 0.02 & 0.06 & $-0.348^{\star *}$ \\
\hline & Not-worrying & -0.01 & -0.15 & -0.13 & -0.21 & -0.08 & -0.03 & 0.16 & -0.13 & -0.14 \\
\hline & Attention Regulation & 0.12 & -0.23 & -0.15 & $-0.352^{\star *}$ & -0.15 & $-0.253^{*}$ & 0.17 & -0.13 & $-0.329^{* *}$ \\
\hline & Emotional awareness & 0.17 & -0.12 & -0.16 & -0.17 & -0.04 & -0.22 & 0.18 & -0.06 & -0.19 \\
\hline & Self-regulation & 0.21 & -0.01 & -0.02 & $-0.488^{\star * *}$ & -0.11 & $-0.326^{\star *}$ & 0.20 & 0.07 & $-0.404^{\star *}$ \\
\hline & Body Listening & 0.19 & -0.15 & -0.10 & $-0.326^{\star *}$ & -0.08 & -0.19 & 0.02 & -0.04 & $-0.263^{*}$ \\
\hline & Trusting & 0.20 & 0.14 & -0.12 & $-0.475^{\star * *}$ & -0.23 & $-0.4^{\star \star}$ & 0.04 & 0.08 & $-0.477^{\star * *}$ \\
\hline \multirow[t]{2}{*}{ RFQ_8 } & RFQ_C & 0.18 & 0.06 & 0.16 & -0.22 & -0.19 & -0.12 & -0.15 & 0.17 & -0.23 \\
\hline & RFQ_U & 0.00 & $-0.255^{\star}$ & -0.07 & $0.319^{*}$ & 0.22 & $0.289^{*}$ & 0.01 & -0.15 & $0.355^{* *}$ \\
\hline \multirow[t]{4}{*}{ EQ-15 } & TOT & $0.251^{*}$ & $0.255^{*}$ & 0.24 & -0.14 & -0.16 & -0.18 & 0.00 & $0.323^{* *}$ & -0.20 \\
\hline & Cognitive Empathy & 0.19 & 0.08 & 0.03 & 0.01 & -0.10 & -0.09 & 0.05 & 0.13 & -0.07 \\
\hline & Emotional Reactivity & 0.16 & 0.16 & $0.269^{*}$ & 0.11 & -0.05 & 0.07 & -0.12 & $0.256^{*}$ & 0.06 \\
\hline & Social Skills & 0.17 & $0.258^{\star}$ & 0.19 & $-0.309^{\star}$ & -0.16 & $-0.281^{\star}$ & 0.05 & $0.271^{*}$ & $-0.323^{\star \star}$ \\
\hline
\end{tabular}

${ }^{*} p<0.05$, two-tailed; ${ }^{* *} p<0.01$, two-tailed; ${ }^{* * *} p<0.001$, two-tailed. 
The increased expression of PLAYFULNESS and CARE in psychotherapists is in line with our expectations, since such emotional dispositions are involved in positive social interchanges and play a crucial role in establishing the therapeutic alliance. CARE and PLAYFULNESS are the two emotional dimensions around which the therapy gravitates. The first-one is related to the process of taking care and the second with the process of exploring together within a protected "transitional" space (Winnicott, 1967). Moreover, the significant reduction in the RAGE/ anger disposition is also coherent with the prevalence of positive cooperative interactions over competitive and aggressive interactions. Interestingly, psychotherapists also show a robust overexpression of the Spirituality scale, indicating that the process of taking care of other's mental health may have something to do with the feeling of belonging to a wider spiritual dimension (Brownell, 2015).

Interestingly, a recent study with the ANPS revealed the existence of three common emotional profiles in non-clinical standard population: low negative emotional, balanced and high emotional profiles (Orri et al., 2017). Our studies may indicate the presence of a fourth character, that we may call the positive socio-emotional profile, characterized by the increased expression PLAY, CARE and of Spirituality and by a decreased expression of RAGE. Such profile may orient towards relationships based more on cooperative and care taking interactions than on competitive and aggressive interactions. It remains to be established if the positive socio-emotional profile is common only among psychotherapists or if it may be evident also in other professions characterized by the process of caring, such as doctors, priests, educators, etc..

The second result of our investigation indicates that the emotional profile is not influenced by the clinical training for psychotherapist, which also includes a personal therapeutic route. Indeed, there are not differences in the ANPS scales between the group of expert psychotherapists and the group of students beginning the specialization school. This result confirms that the emotional profile is a stable configuration of individual personality (Montag \& Reuter, 2014). Moreover, such result also indicates that the positive socio-emotional profile may influence the choice to become a psychotherapist. At the moment, we are not able to ascertain which factors influenced the emotional personality of psychotherapists. However, previous studies with the ANPS revealed that genetic factors play an important role (Montag \& Reuter, 2014; Montag et al., 2016).

Interestingly, our data also show that the positive socio-emotional dispositions are intrinsically related to certain relational competencies essential for psychotherapy. In particular, we found that SEEKING/curiosity, PLAYFULNESS/joy and CARE/nurturance positively correlates with empathy and PLAYFULNESS/joy is also related to the reflective functioning (Table 4). This result strongly indicates that these intersubjective skills are routed on stable emotional dimensions of individual personality. Such finding is still more robust if we consider that the experience of training does not modify the reflective functioning quotient (RFQ) and the empathic quotient (EQ). Indeed, all indexes of such functions are not 
significantly different between psychotherapists and students (Table 3). This surprising result drives us to consider the evidence that the deep knowledge of others and the ability to mentalize may not be taught, since they are based upon individual attitudes which act at an implicit and pre-verbal operational level (Schore, 1994).

On the other hand, the training for psychotherapist has a profound impact on "interoceptive awareness", since all indexes of such function are greater in psychotherapists compared to students (apart the index of "not warring"). Probably, this may be due to the fact that the training in the Gestalt therapy is overtly oriented to increase subjective sensitivity on interoceptive emotional perceptions (Spagnuolo Lobb, 2018; Macaluso, 2020). According to a Gestalt-oriented approach, interoceptive awareness is expression of what we call the Aesthetic Relational Knowledge (Hildebrand, 1893), a concept concerning the therapist's empathic involvement that includes the function of care and highlights how the sensitive response to the movement of the other is not only embodied (i.e. identification with the movement/emotion of the other) but also resonant (i.e. identification with the movement/emotion of those who co-created that experience) (Spagnuolo Lobb, 2018). Recent neuroscientific investigations showed that what we call Aesthetic Relational Knowledge is routed in the viscero-sensori-motor processes that allows empathy, the deep knowledge of the other (Freedberg \& Gallese, 2007; Heimann, Umiltà, \& Gallese, 2013; Umiltà et al., 2012). Indeed, when we are exposed to the emotions of the other, for example the crying, we know the "tension-toward" that is contained in that crying, but also what has contributed to giving it that shape.

Although interoceptive emotional awareness is strongly influenced by training, it is also partially related to the emotional personality profile. Indeed, our data indicate that FEAR/anxiety and SADNESS/separation distress are negatively correlated with almost all indexes of interoceptive awareness. Interestingly, FEAR and SADNESS are also negatively related to the reflective functioning and to "social skills", an index of the Empathic Quotient (EQ) (Table 4). Taken together, such findings show that negative emotionality prevent intersubjective competencies. This fact may be presumably due to the prevalence of avoidant dispositions that do not favour the establishment of positive social contacts.

In sum, our main findings are that:

1) Psychotherapists share a common emotional profile of personality based on an increased expression of positive dispositions (PLAYFULNESS, CARE, Spirituality) and a decreased expression of RAGE;

2) Such emotional profile is not due to the experience of training, but is an individual pre-requisite which may orient the choice to become a psychotherapist;

3) The emotional dimensions of individual personality are strictly related to interoceptive awareness, reflective functioning and empathy;

4) Between all measures of relational and emotional competences only interoceptive awareness is significantly modified by the experience of training, while 
empathy and reflective functioning are not.

To our knowledge, this is the first study that directly and empirically investigates the emotional characters of personality in psychotherapists and our data give some promising indication that should be deepened in future investigation. The evidence that intersubjective competences are routed into the basic emotional substrates of individual personality has been partially anticipated by the work of Orri et al. (2017). However, our study shows for the first time a direct correlation between each basic emotional disposition and certain features that characterize the individual abilities to be tuned with the other, aware of what is going on in the relationship and able to elaborate the emotional interchanges at a mental level.

Our investigation is a pilot study that necessitates further integrative researches. For example, we do not know if the positive socio-emotional profile characterizes all therapists, or if it is common only to the subclass of Gestalt-phenomenological clinicians that we envisioned in our investigation. Therefore, a first proposal is to extend our empirical research with clinicians belonging to other psychotherapeutic approaches. Another important direction for further research would be to ascertain with more precision which relational competences are dependent upon the individual personality and which may be modified by training or other experiential factors. This could be of great support for training programs.

\section{Conflicts of Interest}

The authors declare no conflicts of interest regarding the publication of this paper.

\section{References}

Alcaro, A., Carta, S., \& Panksepp, J. (2017). The Affective Core of the Self. A NeuroArchetypical Perspective on the Foundations of Human (and Animal) Subjectivity. Frontiers in Psychology, 8, 1424. https://doi.org/10.3389/fpsyg.2017.01424

Allison, C., Baron-Cohen, S., Wheelwright, S., Stone, M. H., \& Muncer, S. J. (2011). Psychometric Analysis of the Empathy Quotient (EQ). Personality and Individual Differences, 51, 829-835. https://doi.org/10.1016/j.paid.2011.07.005

Beutler, L. E., Malik, M. L., Alimohamed, S., Harwood, T. M., Talebi, H., Noble, S., \& Wong, E. (2004). Therapist Variables. In M. J. Lambert (Ed.), Bergin and Garfield's Handbook of Psychotherapy and Behavior Change (5th ed., pp. 227-306). New York: Wiley.

Bloom, D. J. (2009). The Phenomenological Method of Gestalt Therapy: Revisiting Husserl to Discover the Essence of Gestalt Therapy. Gestalt Review, 13, 277-295. https://doi.org/10.5325/gestaltreview.13.3.0277

Brownell, P. (2015). Spiritual Competency in Psychotherapy. New York: Springer. https://doi.org/10.1891/9780826199348

Calì, G., Ambrosini, E., Picconi, L., Mehling, W. E., \& Committeri, G. (2015). Investigating the Relationship between Interoceptive Accuracy, Interoceptive Awareness, and Emotional Susceptibility. Frontiers in Psychology, 6, 1202. 
https://doi.org/10.3389/fpsyg.2015.01202

Coenen, V. A., Schlaepfer, T. E., Maedler, B., \& Panksepp, J. (2011). Cross-Species Affective Functions of the Medial Forebrain Bundle-Implications for the Treatment of Affective Pain and Depression in Humans. Neuroscience \& Biobehavioral Reviews, 35, 1971-1981. https://doi.org/10.1016/j.neubiorev.2010.12.009

Dahl, H. S., Rossberg, J. I., Bogwald, K. P., Gabbard, G. O., \& Hoglend, P. A. (2012). Counter Transference Feelings in One Year of Individual Therapy: An Evaluation of the Factor Structure in the Feeling Word Checklist-58. Psychotherapy Research, 22, 12-25. https://doi.org/10.1080/10503307.2011.622312

Davis, K., \& Panksepp, J. (2011). The Brain's Emotional Foundations of Human Personality and the Affective Neuroscience Personality Scales. Neuroscience \& Biobehavioral Reviews, 35, 1046-1058. https://doi.org/10.1016/j.neubiorev.2011.04.004

Davis, K., Panksepp, J., \& Normansell, L. (2003). The Affective Neuroscience Personality Scales: Normative Data and Implications. Neuropsychoanalysis, 5, 57-69. https://doi.org/10.1080/15294145.2003.10773410

Dinger, U., Strack, M., Sachsse, T., \& Schauenburg, H. (2009). Therapists' Attachment, Patients' Interpersonal Problems and Alliance Development Overtime in Inpatient Psychotherapy. Psychotherapy: Theory, Research, Practice, Training, 46, 277-290. https://doi.org/10.1037/a0016913

Farinelli, M., Panksepp, J., Gestieri, L., Maffei, M., Agati, R., Cavolani, D., Pedone, V., \& Northoff, G. (2015). Do Brain Lesions in Stroke Affect Basic Emotions and Attachment? Journal of Clinical and Experimental Neuropsychology, 37, 595-613. https://doi.org/10.1080/13803395.2014.991279

Flückiger, C., Del Re, A. C., Wampold, B. E., \& Horvath, A. O. (2018). The Alliance in Adult Psychotherapy: A Meta-Analytic Synthesis. Psychotherapy (Chic), 55, 316-340. https://doi.org/10.1037/pst0000172

Fonagy, P., Luyten, P., Moulton-Perkins, A., Lee, Y. W., Warren, F., Howard, S., Ghinai, R., Fearon, P., \& Lowyck, B. (2016). Development and Validation of a Self-Report Measure of Mentalizing: The Reflective Function Questionnaire. PLOS ONE, 11, e0158678. https://doi.org/10.1371/journal.pone.0158678

Francesetti, G., Alcaro, A., \& Settanni, M. (2020). Panic Disorder: Attack of Fear or Acute Attack of Solitude? Convergences between Affective Neuroscience and Phenomenological-Gestalt Perspective. Research in Psychotherapy Psychopathology Process and Outcome, 23, 77-87. https://doi.org/10.4081/ripppo.2020.421

Freedberg, D., \& Gallese, V. (2007). Motion, Emotion and Empathy in Aesthetic Experience. Trends in Cognitive Sciences, 11, 197-203.

https://doi.org/10.1016/j.tics.2007.02.003

Freud, S., Strachey, J., \& Freud, A. (1910). The Standard Edition of the Complete Psychological Works of Sigmund Freud Vol. 11: Five Lectures on Psycho-Analysis, Leonardo da Vinci, and Other Works. London: Hogarth Press and the Institute of Psychoanalysis, 1957.

Fuchshuber, J., Hiebler-Ragger, M., Kresse, A., Kapfhammer, H. P., \& Unterrainer, H. F. (2019). Do Primary Emotions Predict Psychopathological Symptoms? A Multigroup Path Analysis. Front Psychiatry, 10, 610. https://doi.org/10.3389/fpsyt.2019.00610

Gabbard, G. O. (2014). Psychodynamic Psychiatry in Clinical Practice. Washington DC: American Psychiatric Association Publishing.

Giacolini, T., Ardizzone, I., Davis, K. L., Ferrara, M., Piccioni, L., Terrinoni, A., \& Sabatello, U. (2017). Brain Emotional Systems: The Italian Version of the ANPS-Affective Neuroscience Personality Scales 2.4 (Reliability and Validity). Clinical Neuropsychia- 
try, 14, 263-274.

Greenberg, J. (2001). The Analyst's Participation: A New Look. Journal of the American Psychoanalytic Association, 49, 359-381. https://doi.org/10.1177/00030651010490020801

Heimann, P. (1950). On Counter-Transference. The International Journal of Psychoanalysis, 31,81 .

Heinonen, E., \& Nissen-Lie, H. A. (2020). The Professional and Personal Characteristics of Effective Psychotherapists: A Systematic Review. Psychotherapy Research, 30, 417-432. https://doi.org/10.1080/10503307.2019.1620366

Hersoug, A. G., Høglend, P., Havik, O., von der Lippe, A., \& Monsen, J. (2009). Therapist Characteristics Influencing the Quality of Alliance in Long-Term Psychotherapy. Clinical Psychology \& Psychotherapy, 16, 100-110. https://doi.org/10.1002/cpp.605

Hersoug, A. G., Høglend, P., Monsen, J. T., \& Havik, O. E. (2001). Quality of Working Alliance in Psychotherapy: Therapist Variables and Patient/Therapist Similarity as Predictors. Journal of Psychotherapy Practice and Research, 10, 205-216.

Jacobs, L., \& Hycner, R. (2009). Relational Approaches in Gestalt Therapy. New York: A Gestalt Press Book.

Karterud, S., Pedersen, G., Johansen, M., Wilberg, T., Davis, K., \& Panksepp, J. (2016). Primary Emotional Traits in Patients with Personality Disorders. Personality and Mental Health, 10, 261-273. https://doi.org/10.1002/pmh.1345

Kazdin, A. E. (2009). Understanding How and Why Psychotherapy Leads to Change. Psychotherapy Research, 19, 418-428. https://doi.org/10.1080/10503300802448899

Kristiansen, V. R., Handeland, T. B., Lau, B., Søderstrøm, K., Håkansson, U., \& Øie, M. G. (2019). Trauma in Childhood and Adolescence and Impaired Executive Functions Are Associated with Uncertain Reflective Functioning in Mothers with Substance Use Disorder. Addictive Behaviors Reports, 11, Article ID: 100245. https://doi.org/10.1016/j.abrep.2019.100245

Lingiardi, V., Muzi, L., Tanzilli, A., \& Carone, N. (2018) Do Therapists' Subjective Variables Impact on Psychodynamic Psychotherapy Outcomes? A Systematic Literature Review. Clinical Psychology \& Psychotherapy, 25, 85-101. https://doi.org/10.1002/cpp.2131

Macaluso, M. A. (2020). Deliberateness and Spontaneity in Gestalt Therapy Practice. British Gestalt Journal, 29, 30-36.

Mehling, W. E., Price, C., Daubenmier, J. J., Acree, M., Bartmess, E., \& Stewart, A. (2012). The Multidimensional Assessment of Interoceptive Awareness (MAIA). PLoS ONE, 7, e48230. https://doi.org/10.1371/journal.pone.0048230

Montag, C., \& Reuter, M. (2014). Disentangling the Molecular Genetic Basis of Personality: From Monoamines to Neuropeptides. Neuroscience \& Biobehavioral Reviews, 43, 228-239. https://doi.org/10.1016/j.neubiorev.2014.04.006

Montag, C., Hahn, E., Reuter, M., Spinath, F. M., Davis, K., \& Panksepp, J. (2016). The Role of Nature and Nurture for Individual Differences in Primary Emotional Systems: Evidence from a Twin Study. PLoS ONE, 11, e0151405.

https://doi.org/10.1371/journal.pone.0151405

Montag, C., Widenhorn-Müller, K., Panksepp, J., \& Kiefer, M. (2017). Individual Differences in Affective Neuroscience Personality Scale (ANPS) Primary Emotional Traits and Depressive Tendencies. Comprehensive Psychiatry, 73, 136-142.

https://doi.org/10.1016/j.comppsych.2016.11.007

Morandotti, N., Brondino, N., Merelli, A., Boldrini, A., De Vidovich, G. Z., Ricciardo, S., 
Abbiati, V., Ambrosi, P., Caverzasi, E., Fonagy, P., \& Luyten, P. (2018). The Italian Version of the Reflective Functioning Questionnaire: Validity Data for Adults and Its Association with Severity of Borderline Personality Disorder. PLoS ONE, 13, e0206433. https://doi.org/10.1371/journal.pone.0206433

Muncer, S. J., \& Ling, J. (2006). Psychometric Analysis of the Empathy Quotient (EQ) Scale. Personality and Individual Differences, 40, 1111-1119.

https://doi.org/10.1016/j.paid.2005.09.020

Norcross, J. C., \& Wampold, B. E. (2011). Evidence-Based Therapy Relationships: Research Conclusions and Clinical Practices. Psychotherapy, 48, 98-102. https://doi.org/10.1037/a0022161

Orri, M., Pingault, J. B., Rouquette, A., Lalanne, C., Falissard, B., Herba, C., Côté, S. M., \& Berthoz, S. (2017). Identifying Affective Personality Profiles: A Latent Profile Analysis of the Affective Neuroscience Personality Scales. Scientific Reports, 7, Article No. 4548. https://doi.org/10.1038/s41598-017-04738-x

Panksepp, J. (1998). Affective Neuroscience: The Foundations of Human and Animal Emotions. Oxford: Oxford University Press.

Panksepp, J. (2006). Emotional Endophenotypes in Evolutionary Psychiatry. Progress in Neuro-Psychopharmacology \& Biological Psychiatry, 30, 774-784. https://doi.org/10.1016/j.pnpbp.2006.01.004

Panksepp, J., \& Biven, L. (2012). The Archaeology of Mind: Neuroevolutionary Origins of Human Emotions. New York: W.W. Norton \& Company.

Pascazio, L., Bembich, S., Nardone, I. B., Vecchiet, C., Guarino, G., \& Clarici, A. (2015). Validation of the Italian Translation of the Affective Neuroscience Personality Scales. Psychological Reports, 116, 97-115. https://doi.org/10.2466/08.09.PR0.116k13w4

Perls, F., Hefferline, R., \& Goodman, P. (1951). Gestalt Therapy. Excitement and Growth in the Human Personality. Highland, NY: Gestalt Journal Press.

Polster, E. (1987). Every Person's Life Is Worth a Novel. New York: W.W. Norton \& Co.

Pulver, A., Kiive, E., \& Harro, J. (2020). Reward Sensitivity, Affective Neuroscience Personality, Symptoms of Attention-Deficit/Hyperactivity Disorder, and TPH2-703G/T (rs4570625) Genotype. Acta Neuropsychiatrica, 1-10.

https://doi.org/10.1017/neu.2020.18

Robine, J.-M. (2001). From Field to Situation. In J.-M. Robine (Ed.), Contact and Relationship in a Field Perspective (pp. 95-107). Bordeaux: L'Exprimerie.

Robine, J.-M. (2015). Social Change Begins with Two. Siracusa: Istituto di Gestalt HCC Italy Publ. Co. http://www.gestaltitaly.com

Schore, A. N. (1994). Affect Regulation and the Origin of the Self. Mahwah, NJ: Erlbaum.

Senese, V. P., De Nicola, A., Passaro, A., \& Ruggiero, G. (2016). The Factorial Structure of a 15-Item Version of the Italian Empathy Quotient Scale. European Journal of Psychological Assessment, 34, 344-351. https://doi.org/10.1027/1015-5759/a000348

Spagnuolo Lobb, M. (2013). The Now-for-Next in Psychotherapy. Gestalt Therapy Recounted in Post-Modern Society. Milan: FrancoAngeli.

Spagnuolo Lobb, M. (2017a). From Losses of Ego Functions to the Dance Steps between Psychotherapist and Client. Phenomenology and Aesthetics of Contact in the Psychotherapeutic Field. British Gestalt Journal, 26, 28-37.

Spagnuolo Lobb, M. (2017b). Phenomenology and Aesthetic Recognition of the Dance between Psychotherapist and Client: A Clinical Example. British Gestalt Journal, 26, 50-56.

Spagnuolo Lobb, M. (2018). Aesthetic Relational Knowledge of the Field: A Revised Con- 
cept of Awareness in Gestalt Therapy and Contemporary Psychiatry. Gestalt Review, 22, 50-68. https://doi.org/10.5325/gestaltreview.22.1.0050

Stern, D. (2004). The Present Moment in Psychotherapy and Everyday Life. New York: W. W. Norton \& Company.

Umiltà, M. A., Berchio, C., Sestito, M., Freedberg, D., \& Gallese, V. (2012). Abstract Art and Cortical Motor Activation: An EEG Study. Frontiers in Human Neuroscience, 6, 311. https://doi.org/10.3389/fnhum.2012.00311

Wernicke, J., Li, M., Sha, P., Zhou, M., Sindermann, C., Becher, B., Kendrick, K. M., \& Montag, C. (2019). Individual Differences in Tendencies to Attention-Deficit/Hyperactivity Disorder and Emotionality: Empirical Evidence in Young Healthy Adults from Germany and China. ADHD Attention Deficit and Hyperactivity Disorders, 11, 167182. https://doi.org/10.1007/s12402-018-0266-9

Winnicott, D. W. (1949). Hate in the Counter-Transference. The International Journal of Psychoanalysis, 30, 69.

Winnicott, D. W. (1967). Playing and Reality. London: Routledge.

Yontef, G. M. (2001). Relational Gestalt Therapy. In J.-M. Robine (Ed.), Contact and Relationship in a Field Perspective (pp. 79-94). Bordeaux: L'Exprimerie. 